equal to an annual rate of $2 \cdot 6$ per 1000 , which was 0.2 below the average rate from the same diseases in the twenty-eight English towns. The deaths referred to diarrhoea in the eight towns, which had been 41 and 51 in the previous two weeks, declined last week to 29 , which was little more than half the number in the corresponding week of last year; 18 occurred in Glasgow. The 11 fatal cases of whooping-cough showed a decline of 3 from the number in the preceding week, and included 9 in Glasgow and 3 in Paisley. The 10 deaths from "fever" exceeded the number in any recent week; 6 were returned in Glasgow and 2 in Edinburgh. Seven of the 8 fatal cases of scarlet fever, and all the 4 deaths from measles, occurred in Glasgow. A fatal case of small-pox, the first recorded in any of the eight towns since June last, was returned in Glasgow. The deaths referred to acute diseases of the respiratory organs, which had been 55 and 48 in the preceding two weeks, rose again last week to 57 , but were 6 below the number returned in the corresponding week of last year. The causes of 58 , or 13.8 per cent, of the deaths in the eight Scotch towns last week were not certified.

\section{HEALTH OF DUBTIN.}

The rate of mortality in Dublin, which had been $20 \cdot 1$ and 22.8 per 1000 in the preceding two weeks, further rose to 26.7 in the week ending the 12th inst. During the first ten weeks of the current quarter the death-rate in the city averaged $23 \cdot 2$ per 1000 , the rate during the same period being equal to $19 \cdot 0$ in London and 15.6 in Edinburgh. The 181 deaths in Dublin last week showed an increase of 27 upon the number in the previous week, and included 27 which were referred to the principal zymotic diseases, against 11 and 23 in the preceding two weeks; 18 resulted from diarrhœa, 6 from "fever" (typhus, enteric, or simple), 2 from whooping-cough, 1 from scarlet fever, and not one either from small-pox, measles, or diphtheria. These 27 deaths were equal to an annual rate of 4.0 per 1000 , the rate from the same diseases being 1.5 in Edinburgh and 2.3 in London. The fatal cases of diarrhœa, which had been 7 and 14 in the preceding two weeks, further rose to 18 last week; the deaths referred to "fever" also showed a further increase upon recent weekly numbers; while the fatality of whoopingcough and of scarlet fever showed a slight decline from that recorded in the previous week. One inquest case and 2 deaths from violence were registered; and 49, or more than a fourth, of the deaths occurred in public institutions. The deaths both of infants and of elderly persons showed a marked increase upon the numbers in the preceding week. The causes of 32, or nearly 18 per cent., of the deaths registered during the week were not certified.

\section{THE SERVICES.}

Deputy Surgeon-General Edmund Greswold M'Dowell, who was created a Companion of the Bath for his services as Principal Medical Officer in the Soudan campaign of 1884 , has been appointed in a similar capacity on the Staff at Woolwich.

Volunterer Mmdicat Staff Corps.-Surgeon-General Sir William Guyer Hunter, M.D., K.C.M.G., to be Honorary Surgeon-Commandant.

AdMIRALTY. - The following appointments have been made:-Fleet-Surgeon Nicholas $T$. Connolly, additional, to the President; Staff Surgeon William P. M. Boyle, to the Gannett; Fleet Surgeon James H. Martin, to the Duncan; Fleet Surgeon Charles Strickland, to the Monarch; Staff Surgeon Fleetwood Buckle, M.D., to the Active; Staff Surgeon Henry Beaumont, to the Rover; Staff Surgeon William B. Drew, to the Volage; Staff Surgeon Richard D. White, M.D., to the Calypso; Staff Surgeon Alexander B. Tronsdell, M.B., to Bermuda Hospital; Staff Surgeon Richard B. Brown, M.B., to the Tenedos; Surgeons Matthew Degan and Alex. G. Andrews, to the Monarch; Surgeon James C. Dow, M.B., to the Active; Surgenn Edward B. Townsend, to the Rover; Surgeon James B. Wray, to the Volage; Surgeon James Porter, M.B., to the Calypso; Surgeon Alexander M. French, to the Pembroke; Surgeon Alexander G. Wildey, to the Boscawen; Surgeon Edwd. C. Wood, M.D., to the Banterer; Surgeon Edward R. D. Fasken, additional, to the Duncan; Surgeon Myles O'C. MrSwiny, additional, to the Pembroke; and Surgeon John Jenkins, to the Impregnable.
Rifie Volunteens, - 3rd Lancashire: Surgeon Luke Fisher, M.D., is granted the honorary rank of SurgeonMajor.

\section{Coxtepondence.}

$$
\text { "Audi alteram partem." }
$$

\section{NITRO-GL Y CERINE TABLETS. To the Editor of THE haNCET.}

SIR,-The admission of only one preparation of nitroglycerine into the British Pharmacopœia is, I am sure, a decided mistake. The tablets are undoubtedly sometimes useful, but in many cases their administration is inadmissible. The chief employment of nitro-glycerine as a medicinal agent is as a remedy for angina pectoris and allied diseases, our object being to secure the full physiological action of the drug with as little delay as possible. Patients vary remarkably in their susceptibility to the action of this peculiar remedy. One man takes the six-hundredth of a grain, and suffers for hours afterwards from intense headache, which incapacitates him from work of any kind; whilst another patient will take fifteen or twenty minims of the 1 per cent. solution ten or a dozen times a day, not only without inconvenience but with the greatest possible benefit. Each of the officinal tablets contains one-hundredth of a grain, and it is somewhat difficult to understand how the dose could be conveniently regulated, if they alone were to be employed. The small-dose man would find his time pretty fully occupied if he had to divide each little tablet weighing only two grains and a half into six equal parts whilst his large-dose colleague might experience some inconvenience in swallowing fifteen or twenty chocolate drops at a dose, especially if he were suddenly arrested by an anginal attack whilst crossing a busy thoroughfare. With the 1 per cent. alcoholic solution the dose can be regulated to a nicety, and the patient need not know exactly how much he is taking. Moreover, nitro-glycerine is nowadays very rarely given alone, for it is found to act more efficaciously and much more promptly if administered in the liquid form in conjunction with certain diffusible stimulants and aromatics, which facilitate its absorption and increase its rapidity of action. A delay of a few minntes in the treatment of many diseases is of no importance; but a man in the agony of a paroxysm of angina pectoris is naturally anxious to get relief, and objects to stand waiting about until a number of little chocolate drops feel inclined to exert their action. The question of expense, too, has to be considered. Many patients take fifteen minims of the 1 per cent. solution every two or three hours, with an extra dose at the onset of every attack. The medicine in solution costs very little; but if these large doses were translated into the officinal form they would come rather expensive, for a $4 s .6 d$. box would be gone in no time. I once had a patient who took 27,532 minims of the 1 per cent. solution in three months. This in tablets, at the price at which they are now sold, would mean something like $£ 200$ a year, all for one drug. It is quite true that angina pectoris occurs chiefly amongst the wealthy classes, but at this rate a man to have it badly ought to be a millionaire. It is at all times a terrible complaint, but the introduction of these tabletsunless we disregard the injunctions of the Pharmacopoiawill add another to its already long list of horrors. It has been hinted that the 1 per cent. solution has been purposely omitted from motives of prudence; but it is hardly conceivable that such can be the case, for anyone wishing to obtain nitro-glycerine for illegal purposes could separate it equally well from the tablets as from the solution. When a drug is made officinal, directions are usually given for its preparation; but in this particular instance it is left to the chemist to make it according to his fancy, and it will be a subject for congratulation if his maiden efforts do not afford occupation for a coroner's jury. Again, no tests or characters are given for this potent drug, and in future there will be nothing to distinguish the harmless chocolate drop from the nitro-glycerine tablet. Nost of our medicated lozenges are stamped with the vame of the particular poison which they contain, as an indication that they are not to be taken in unlimited quantities; but presumably no such precaution 
need be adopted with these new agents of destruction. The framers of the British Pharmacopoeia will do well to reconsiluer their decision, for undoubtedly a serious mistake has been committed. The dose they recommend-from one to tro tablets-would in some cases be dangerously large, whilst in others it would prove quite inadequate.

I am, Sir, your obedient servant,

Wermouth-street, W., Sept. 1885. William MuRRELL, M.D.

THE "HOMES" OF THE WINDSOR POOR AND THE QUEEN'S JUB TIEE.

\section{To the Editor of THE LANCET.}

SIr,-As you unanswerably point out in your leading article of Sept. 5th, the Corporation of Windsor have never used the powers with which the Legislature so amply armed them, as long ago as 1868, for dealing with dwellings, either by demolition or otherwise, that were structurally so imperfect as to be unfit for human habitation. This, Sir, has been and is my contention; and I have been-more or less, indeed, since 1876-fighting a fight here on these lines, in which it is, locally so far, one man against many. To comprehend what is amiss, and the extent of the mischief, look at this dreadful picture, officially certified to be true, of "life in death" in Windsor. It cannot be too often proclaimed, nor too widely known, that, according to the ruling of the medical officer of health here, he "does not fee? justified in condemning" ten houses, harbouring fifty souls, that have neither closet nor privy, because these privileged ones have the right to use other people's closets on the opposite side of the court; and, moreover, every room within these luxuriantly-appointed dwellings has "a fireplace and a sash window"! No closet, but "a fireplace and a sash window." Constructive compensation anyhow, but put up, on the whole, a little too much like the condition of the man who had no clothes but a pair of straps and a shirt-collar, to be altogether original. This invaluable right to stroll about thus delicately into other people's closets is disputed. Here, however, is where, in such nice matters of civilisation, civic oversight draws the line. What primitive homeliness is there not in this free reading of the humanities! Of what unconventional elements is not the purity of the firesides of Windsor's poor compounded! If you have only "a fireplace and a sash window," then, Sir, the right, just as it has come down to us from the ancient Briton, is yours to range at pleasure over other people's closets. In the bowers of Arcadia there could be nothing to beat this Such are some of the liberties of the old men and children, the young men and maidens, of South-place, in the Roya borough. Conceive a medical officer of health discussing such a question, in such a spirit, seriously! The dwellers in these shades have to cross the street by night and day, in grievous peril alike of malaria and immodesty, to negotiate with their neighbours for all sanitary purposes and "rights" whatsoever; and the public conscience, notwithstanding, holds its peace. This, Sir, has gone on for years, and there are many quarters in the town, much nearer to the Castle walls, where the cholera, if it came among us, would make a habitation, but where the poor cannot find a home. The Special Commissioner of THE LANCET has made it plain to the authorities here that there is an obligation on them to lose no time, not an hour, in setting the houses of the poor in order. This is, indeed, only in corroboration of all that has been said, hitherto unhappily with none effect, by Charles Knight, a foremost and famous Windsor man, in 1859 ; by the Builder newspaper in 1871; and by myself almost continuously ever since 1876. The "homes" of the Windsor poor were a scandal to King William IV. more than fifty years ago, and vexed the soul of the late Prince Consort until the day of his death. The consort of the Queen from the first perceived how the poor of Windsor, notwithstanding their wealth of "fireplaces and sash windows," were being demoralised, and he beneficently sought to prevent it. In June, 1886, will be begun the jubilee of the reign of Queen Victoria, Which will certainly leave its mark on England and perbaps upon the world. Might not such a year of privilege be made to leare some very special mark on ancient, royal, and loyal Windsor? Our slums are our weakness, our shame, and our reproach, If in the year of jubilee we can set the houses of our poor in order, we shall do much for hygiene, but much more for humanity; we shall rise up and build a modern Windsor; and thus we shall best do honour to her who will have reigned over us for fifty years, and to the memory of that Consort who in her heart will ever re1gn. It is, Sir, the testimony of all ages that the highest interests and the supremest happiness of the castle and the cottage, if they are to be abiding, must be one. That this is true we in Windsor, if we are wise, can now bear witness to the latest posterity.

I am. Sir, yours truly,

Holy Trinity Rectory. Windsor, Sept, 7th, 1885 . ARTHUR RoBins, M.A.

\section{To the Editor of THE LANCET.}

SIR,-I received the following letter from Dr. Casey, Medical Officer of Health for Windsor, in reply to my letter published in THE LANCET; and though I do not see how it can affect the subject matter of my letter, still, in justice to Dr. Casey's view of the circumstance, I shall be obliged by your inserting it in your next issue.

Yours faithfully,

Braemar, N.B., Sept. 14th, 1885. W. M. Colisins, M.D.

[COPY.]

Windsor, Sept. 5th, 1885 .

DEAR Sin,- You seem to be imperfectly informed of the circumstances of the case about which you have written to THE LANCET. The facts are these. Having received information (from yourself I think) that the man was walking about while still infectious, I wrote to the Mayor, and was a day or two after informed by him that he had promptly sent a police officer to threaten proceedings; but that he, the officer, was met by a statement from Surgeon-Major Melladew that the man could not be said to be then infectious.

I am, Sir, yours faithfully,

To Dr. W. M. Collins, Braemar, N.B. EDWARD CASEY.

\section{CH OLE R A M A L I G A. \\ To the Editor of THE LANCET.}

SIn,--In answer to criticisms to a previous letter of his, in which he gave an account of a case of English cholera cured in some six hours by certain remedies, and from which case he argued that these same remedies should be equally efficacious in cholera maligna, because the diseases only differ in degree, Dr. Illingworth writes in THE LANCET of the 5th inst., that "it needs no argument to prove that if the two diseases referred to differ only in point of severity, remedies which are successful in the one must prove of use in the other." Of course not; but it lies with Dr. Illingworth to show that the two diseases only differ in point of severity, for 1 think the medical profession in general and those who have had experience in dealing with the two diseases in particular - the disease known as English cholera bilious diarrhœea, or choleraic diarrhœa is very common in India-are not of such opinion.

Then, Dr. Illingworth writes, "Again I assert that they only differ in degree. What evidence is there to the contrary?" Well, I could give a good deal of evidence from my own experience, but such would be more suitable to a paper than to a letter, and will confine myself to saying that the two diseases can nearly always be recognised from the earliest symptoms and in their successive stages. To a patient suffering from English cholera I say, "Do not be afraid; you will be all right again by evening," or morning, as the case may be ; and to the cholera case cheery words too, but no prognosis. Again, I give opiates and stimulants in the severest of cases of English cholera with almost immediate benefit, but these remedies $I$ have found useless in controlling the mildest of cholera cases. But apart from my own experience, there seems to me to be plenty of evidence to the contrary. The two diseases are recognised in our text-books, where the symptoms and treatment of each are given, which would hardly be the case unless the experience of the profession warranted such writing. To give actual proof in medicine is almost, if not quite, impossible; but will venture, with all courtesy, to remind Dr. Illingworth of his own truism, that " simple assertion to the contrary is no proof."

Once more. Dr. Illingworth writes, that " it is difficult to see how they can be quite distinct from each other when 